\title{
Prevalence of genital human papillomavirus infection in Wellington women
}

\author{
Gail E Meekin, Margaret J Sparrow, Rosemary J Fenwicke, Martin Tobias
}

\begin{abstract}
Objectives-To determine prevalence of human papillomavirus (HPV) in Wellington women, to identify risk factors for HPV infection, to correlate presence of HPV with cervical cytology, and to identify characteristics of women infected with HPV but with normal cytology.

Design-Demographic, social, personal and clinical data were collected by a confidential self-administered coded questionnaire. The presence of DNA from HPV types $6 / 11,16+18$ and $31+33$ in cervical scrapes was determined by dotblot DNA hybridisation. All data were correlated with cervical cytology results. Setting and Subjects-Two thousand and twenty one women attending family planning clinics in the Wellington region participated in the study. The mean age of participants was 26 years, $33 \cdot 3 \%$ currently smoked, $\mathbf{7 2 . 3 \%}$ used hormonal contraceptives, $31 \cdot 4 \%$ were married, and $91 \cdot 4 \%$ were of European origin.
\end{abstract}

Results-We found $10.9 \%$ of the study group infected with HPV. HPV types 16 and/or 18 predominated, being detected in $71.5 \%$ of HPV-positive women either alone or with other types. Of those infected $26 \cdot 2 \%$ had multiple infections. Dysplasia $(n=87)$ or atypia $(n=84)$ were observed in $26.7 \%$ of infected women $(n=221)$ and $6.25 \%$ of uninfected women $(n=1792)$. Over $8 \%$ of women with normal smears were HPV positive, and types $16 / 18$ were most common in these women.

Conclusions-Women with cervical dysplasia or atypia were six times more likely to have HPV infection than other women. The main risk factor for HPV infection, particularly with types 16 and/or 18, was multiple $(>5)$ sexual partners in the last year independent of other variables. Multivariate analysis of data showed no independent association between HPV infection and ethnicity, educational background, smoking history, marital status, contraceptive use, age at first sexual intercourse, or number of lifetime sexual partners.

\section{Introduction}

Human papillomavirus (HPV) infection is now the most common sexually transmitted disease in New Zealand.' Human papillomaviruses, particularly types 16 and 18 , have been strongly implicated in the development of cancer of the cervix, vagina, vulva, penis, and anus. ${ }^{2-4}$
The incidence of cervical cancer varies in different countries. In Latin America, the Caribbean, Brazil, Mexico and Peru, high annual incidences of over 20 cases $/ 100000$ have been reported ${ }^{24}$ whereas other countries such as Denmark have a low incidence. ${ }^{5}$ In New Zealand, the incidence of carcinoma-insitu increased $22 \%$ in 1987 compared with 1986, with 1147 new cases reported. ${ }^{6}$ It has been suggested that New Zealand women born around 1957 may have over three times the risk of cervical cancer as those born around 1932 . Over the last 10 years, the standardised rate for New Zealand has been 12.7 cases/100 000 women. ${ }^{6}$ The New Zealand population is composed of different ethnic groups, with a large component of Polynesians. Maori constitute $12 \%$ of the population and Pacific Islanders a further $3 \%{ }^{8}$ Cancer of the cervix is the third most common cancer in Maori women; its incidence has increased since 1980 to be currently over 30 cases/yr/100 000 women, three times the rate for non-Maori women. ${ }^{6} 9$

There have been no published epidemiological studies of the prevalence of genital HPV infection in New Zealand. Studies overseas have found varying prevalence rates of HPV ranging from $10 \%$ to $80 \%$ dependent upon the population studied and the methods used for detection of HPV. ${ }^{310-12}$ Recently specific risk factors for HPV infection as well as cervical cancer have been investigated. ${ }^{410} 1314$

\section{Objectives}

In this study we aimed to (i) determine the prevalence of human papillomavirus infections (types $6 / 11,16 / 18$ and $31 / 33$ ) in sexually active adult women resident in the greater Wellington area, (ii) identify risk factors for HPV infection, particularly with the 'oncogenic' types of human papillomavirus, (iii) correlate the presence of human papillomavirus with cervical cytology, and (iv) identify the characteristics of women infected with HPV but with normal cervical cytology.

\section{Patients and methods}

Women attending family planning clinics in Wellington city (population 147800 ) and Porirua, a dormitory city of 47000 people, were invited to participate in a joint study carried out by the Family Planning Association (FPA) and the New Zealand Communicable Disease Centre (NZCDC). An information sheet was given to each woman and she was required to 
complete a self-administered anonymous numbered questionnaire at the time of examination. Information was sought on age, marital status, race, employment, educational level, smoking, contraceptive usage, sexual history, smear history, pregnancy and parity. A cervical smear was taken with a wooden spatula, and the slide prepared according to normal procedure for cytological examination. The spatula with the remainder of the specimen was placed into sterile transport medium and sent to NZCDC for HPV detection and typing. Specimens were collected over a 9 month period from October 1989 to July 1990.

Questionnaires were sent with specimens to NZCDC; all data, including HPV and cytology results, were entered on computer at NZCDC. Coded HPV typing results were referred back to FPA. Women positive for HPV were informed and invited back for discussion with clinic staff. Smears were examined at a local medical laboratory, results coded, and then sent to NZCDC for entry onto computer. The Bethesda reporting system ${ }^{15}$ was adapted for analysis of cytology results. Atypia (atypical cells of undetermined significance) and dysplasia (low grade and high grade squamous intraepithelial lesions with or without associated HPV changes) ${ }^{15}$ categories were combined for some analyses.

\section{HPV Detection and typing}

HPV DNA hybridisation assays were carried out by the dot-blot technique using radioactively-labelled specific probes of HPV types $6 / 11,16,18,31$, and 33 and alu as human DNA control. HPV clones were a gift from $\mathrm{H}$ zur Hausen, Deutsches Krebsforschungzentrum, Heidelberg, Germany. Cervical scrapes were spun, washed once in phosphate buffered saline (PBS) and cells resuspended in $1 \mathrm{ml}$ PBS before DNA extraction. DNA was extracted from cervical cells using proteinase $\mathrm{K}$ lysis, followed by phenol/chloroform extraction and ethanol precipitation. DNA extracts $(5 \mu \mathrm{l})$ were spotted onto four replicate nylon membranes (Hybond-N, Amersham, UK). Controls were DNA extracts of Hela (HPV 18), Caski (HPV 16, high positive control) and Siha cells (HPV 16, low positive control), and $0 \cdot 1$ ng human alu DNA, HPV 31,33 and 6/11 DNA. Filters were air-dried then denatured, neutralised and fixed by exposure to UV light for $4 \mathrm{~min}$. Prehybridisation in $0.1 \%$ SDS, $50 \%$ formamide, $5 \times$ Denhardts solution, $4 \times$ SSC and $250 \mu \mathrm{g} / \mathrm{ml}$ freshly denatured salmon sperm DNA, was carried out for $1.5 \mathrm{~h}$ at $42^{\circ} \mathrm{C}$.

Filters were then hybridised in the same buffer for $44 \mathrm{~h}$ at $42^{\circ} \mathrm{C}$ with ${ }^{32} \mathrm{P}$-radiolabelled probes for Alu, HPV $6 / 11$ and mixtures of HPV $16+18$, HPV $31+33$. Probes consisted of HPV inserts in $\mathrm{pBr} 322$ vectors and were labelled by nick translation with ${ }^{32} \mathrm{P}$-labelled d-cytosine triphosphate (Amersham, UK). For each probe $1 \times 10^{6} \mathrm{cpm} / \mathrm{ml}$ hybridisation buffer was used. Filters were washed at high stringency $\left(\mathrm{Tm}-17^{\circ} \mathrm{C}\right)$ in $2 \times \mathrm{SSC}, 0.1 \%$ SDS at $68^{\circ} \mathrm{C}$ for $3 \times 45 \mathrm{~min}$, then autoradiographed for $60 \mathrm{~h}$ at $-70^{\circ} \mathrm{C}$ on Hyperfilm MP $\mathrm{X}$-ray film (Amersham, UK) in Cronex cas- settes fitted with intensifying screens. Films were examined and reactions recorded by two observers. Reactions were scored as $+/-$ (visible, but not clearly defined spot), 1+ (clear definition of spot), $2+$ (strong signal confined to spot), 3+ (intense black area which may extend beyond margins of spot). Specimens which hybridised with all probes were tested against the vector $\mathrm{pBr} 322$ to eliminate the possibility of cross reactions with vector sequences. Samples showing indeterminate $(+/-)$ reactions were retested. Quantity of DNA in the sample was monitored by use of the alu human DNA probe; samples which did not hybridise with alu were classed as having insufficient DNA and therefore invalid.

\section{Ethics}

At the time of smear-taking, written informed consent was obtained from each participant. Maximum efforts were made to preserve patient confidentiality at all stages of the study. The study was approved by the Wellington Area Health Board Ethics Committee. An independent patient advocate was appointed.

\section{Statistics}

Bivariate analysis was carried out on all demographic and medical history data in relation to HPV infection status; chi square tests for trend were also calculated where appropriate. Significant risk factors for HPV infection were then analysed using logistic regression models to permit simultaneous control of potential confounding variables (ie, race, education level, marital status, whether they had ever smoked, use of hormonal contraceptives, number of sex partners in last year, lifetime number of sex partners, age at first intercourse). Mantel-Haenszel adjusted odds ratios (OR) and corresponding $95 \%$ Confidence Intervals ( $95 \%$ CI) were calculated from these models.

\section{Results}

\section{Study population}

Two thousand and twenty one women participated, of whom $91.4 \%$ were of European origin, $3.7 \%$ Maori, $2 \cdot 7 \%$ Polynesian, and $2 \cdot 2 \%$ from other ethnic groups. The mean age of participants was $26 \mathrm{yr}$ (range 14-63), the majority were currently unmarried $(68.6 \%)$, and $40 \cdot 1 \%$ had never been married. The group had a high educational background, with $41.9 \%$ of participants having some form of tertiary education, and a further $49.7 \%$ having completed secondary education. Twelve per cent were students, $71.3 \%$ in full employment and $4.6 \%$ unemployed. A third currently smoked; of the nonsmokers, $40.3 \%$ had previously smoked. Contraception was used by $84.6 \%$, hormonal methods being currently used by $72 \cdot 6 \%$ of women. Barrier methods were used by $19 \cdot 4 \%$ of women, sometimes in conjunction with other methods. At some period in time, hormonal contraception had been used for longer than six months by $89.3 \%$ of participants. Intra-uterine devices had been used by $10.5 \%$ of women.

The average age for first sexual intercourse 
Table 1 Distribution of HPV types in HPV-positive cervical scrapes

\begin{tabular}{lcc}
\hline HPV Type & Number & (\%) \\
\hline $6 / 11$ & 30 & $13 \cdot 6$ \\
$31 / 33$ & 32 & $14 \cdot 5$ \\
$6 / 11,31 / 33$ & 1 & $0 \cdot 4$ \\
$16 / 18$ & 101 & $45 \cdot 7$ \\
$6 / 11,16 / 18$ & 34 & $15 \cdot 4$ \\
$16 / 18,31 / 33$ & 15 & $6 \cdot 8$ \\
$6 / 11,16 / 18,31 / 33$ & 8 & $3 \cdot 6$ \\
Total & 221 & $(100)$ \\
\hline
\end{tabular}

was 17.5 y (SD 2.9), with $80 \%$ aged between 15 and $20 \mathrm{y}$. The majority had had more than two sex partners in their life (mean 3.35, SD $1 \cdot 1)$. Thirty six per cent had had more than five lifetime sex partners. In the last year, $67.7 \%$ had only one sex partner, $26.3 \%$ had $2-5$ partners, and a few women $(45,2 \cdot 2 \%)$ had more than five partners (mean number in last year $2 \cdot 3$, SD $0 \cdot 6$ ).

Most women (88.4\%) had previously had a cervical smear; of the study group, $12 \%$ had been referred for further gynaecological investigations. Only 600 women had ever been pregnant, and 304 of these had had children. A number of women had had miscarriages $(109$, $5.4 \%)$ and/or terminations $(321,15 \cdot 9 \%)$. When asked if they had had genital herpes or chlamydia infections $5 \%$ said they had had herpes and $11.6 \%$ chlamydia infections.

\section{Cytology}

Of the total smears examined, $66.9 \%$ were classified by the Bethesda system ${ }^{15}$ as normal, $24.6 \%$ as abnormal or outside normal limits, $4.2 \%$ atypical, and $4.3 \%$ as dysplastic with or without HPV changes. Infection and/or inflammation was recorded in $29.6 \%$ of smears, with $27.4 \%$ of women found to have gardnerella present; $66.7 \%$ of women were recommended for routine follow-up at three years, the current New Zealand Department of Health recommendation.

\section{HPV prevalence and type distribution}

Of the $2019(99.9 \%)$ tested for HPV, 221 $(10.9 \%)$ were found to have HPV infections. Samples from two women contained insufficient DNA for testing. Prevalence of HPV types detected is shown in table 1 . Infection with HPV types 16 and/or 18 was detected in $158 / 221(71.5 \%)$ women. In 58 of these infections, HPV types $16 / 18$ were coexistent with either HPV types $6 / 11$ or $31 / 33$ or both.

\section{Risk factors for HPV infection}

Examination of the characteristics of HPVinfected women showed few differences from uninfected women (table 2). No excess risk of HPV infection was associated with age, whether the woman had ever smoked, educational background, race, or use of hormonal contraceptives. However, women who were currently married were less likely to be HPV positive and women who had never been married were more likely to have HPV infection but these observations were not statistically significant. The major risk factors associated with HPV positivity were sexual history and cervical cytological classification. Women with more than five partners in the last year were over two times (adjusted Odds Ratio $[\mathrm{aOR}]=2 \cdot 2,95 \%$ Confidence Interval

Table 2 Prevalence and risk of HPV infection according to social, demographic and sexual factors

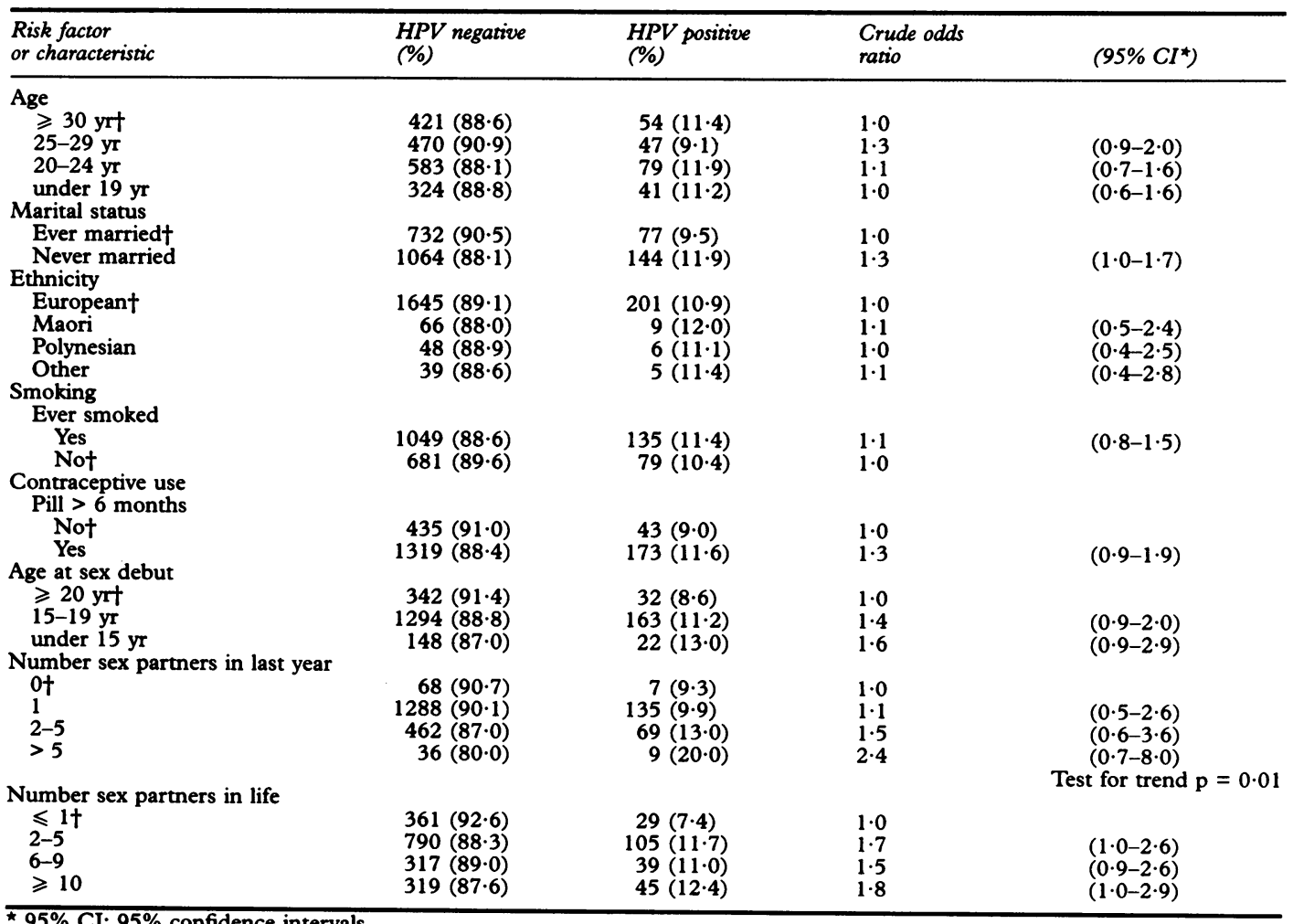
Missing values not included in analysis; totals may vary due to missing values for different variables.
t reference group. 
$[\mathrm{CI}]=1 \cdot 0-4.9)$ more likely to have HPV and 2.9 times (aOR, $\mathrm{CI}=1 \cdot 2-6 \cdot 8$ ) as likely to have an infection with HPV 16 or 18 .

A history of chlamydial infection as reported by participants was associated with HPV infection; $17.9 \%$ of HPV infected women reported having had chlamydia compared to $10.9 \%$ of uninfected women (crude OR $[\mathrm{cOR}]=1 \cdot 8, \mathrm{CI}$ $=1 \cdot 1-2 \cdot 8$ ).

We also noted that women who had a smear within the previous year were more likely $(13.2 \%)$ to have HPV than those who last had a smear over three years ago (3.7\%).

\section{HPV infection and cytology}

The presence of dysplasia was the most significant predictive factor in HPV infection. HPV infection was detected in the cervix of 42 $(48.3 \%)$ of 87 women with dysplasia, 17 $(20 \cdot 25 \%)$ of 84 women with atypia, 50 $(10.1 \%)$ of 495 women with abnormal or outside normal limit smears, and $112(8.3 \%)$ of 1347 women with normal smears. Women with atypia or any degree of dysplasia were 5.8 times (aOR, $\mathrm{CI}=4 \cdot 0-8 \cdot 6)$ more likely to have an HPV infection, and 6.4 times (aOR, $\mathrm{CI}=$ 3.3-5.9) to be infected with HPV types 16 or 18. Apart from mixed infections, HPV types 16 or 18 were detected in two of nine $(22 \cdot 2 \%)$ higher grade lesions (HSIL) (table 3 ) and types 31 or 33 in three HSIL smears. HPV type 6/11 alone was not detected in HSIL smears.

\section{Risk factors for dysplasia}

No increased risk was associated with race or educational background. There was an increased risk for those who had ever smoked and women who had at some time used the contraceptive pill for longer than six months, and a decreased risk for currently married women. These associations disappeared when other possible confounding variables were controlled (age, race, education level, age at first intercourse, sex partners in last year, lifetime sex partners). Increased risk of dysplasia was independently associated with HPV infection, HPV 16/18 infection, $\geqslant 10$ sex partners in life (aOR $=1.9, \mathrm{CI}=1 \cdot 3-2 \cdot 8)$, and over five sex partners in the last year $(\mathrm{aOR}=2 \cdot 6, \mathrm{CI}=$ $1 \cdot 2-5 \cdot 6)$ when other variables were controlled. Increased risk was associated with first intercourse at $15 \mathrm{yr}$ or less $(\mathrm{aOR}=1.4, \mathrm{CI}=$ $1 \cdot 0-2 \cdot 1)$.

\section{Discussion}

We determined the social, demographic and personal characteristics of a group of women attending family planning clinics, and correlated these data with cervical cytology and prevalence of genital human papillomavirus infection. The group comprised young welleducated urban-dwelling women, mean age of 26 y mostly unmarried and of European origin. The proportion of Maori was lower than in the general population, consequently we were unable to identify any specific characteristics in this group.

The prevalence of HPV was $10.9 \%$, which is comparable with results from overseas studies where HPV DNA hybridisation detection methods of equivalent sensitivity have been used in similar sample populations. ${ }^{3^{10-12}} \mathrm{As}$ in overseas studies, HPV types 16 and/or 18 were most prevalent. ${ }^{11116}$

Previously investigated risk factors for cervical cancer are multiple sex partners, ${ }^{24172021}$ age at first intercourse, ${ }^{41720}$ presence of HPV types 16 or $18,^{2-422-25}$ smoking, ${ }^{219}$ multiple parity, ${ }^{418}$ long term use of combined oral contraceptives, 2627 and history of herpes and other sexually transmitted diseases. ${ }^{21}$ In our New Zealand study, some of these risk factors were found to be associated with dysplasia or atypia, and also with HPV infection.

We observed associations between sexual activity, HPV infection, infection with types 16 or 18 , and dysplasia. Women with more than five partners in the previous year were at added risk of HPV infection, especially with types 16 or 18 , and of developing dysplasia. There have been conflicting reports of associations between HPV infection and risk factors for cervical cancer, particularly for risk factors related to sexual activity. ${ }^{4131416}$ Ley and coworkers $^{16}$ reported a strong association between HPV infection and increased numbers of sexual partners, whereas in the Greenland studies, ${ }^{513}$ a high number $(>20)$ of partners appeared to be protective against HPV infection. In our study, no significant associations with HPV infection were observed for age, whether they had ever smoked, educational background, race, marital status, or use of hormonal contraceptives. Other potential risk factors such as lifetime number of sex partners and age at first intercourse were not significant risk factors when other variables

Table 3 Correlation of HPV type with cytology of cervical scrapes

\begin{tabular}{|c|c|c|c|c|c|c|c|c|c|c|}
\hline \multirow[b]{2}{*}{ Cytology } & & \multicolumn{8}{|c|}{ HPV type } & \multirow[b]{2}{*}{ Total } \\
\hline & & $6 / 11$ & $16 / 18$ & $31 / 33$ & $\begin{array}{l}6 / 11 \\
16 / 18\end{array}$ & $\begin{array}{l}6 / 11 \\
31 / 33\end{array}$ & $\begin{array}{l}16 / 18 \\
31 / 33\end{array}$ & $A l l$ & $-v e$ & \\
\hline Normal & & 15 & 53 & 15 & 17 & 1 & 7 & 4 & 1235 & 1347 \\
\hline $\begin{array}{l}\text { Low grade SIL } \\
(\mathrm{CIN} 1 \pm \mathrm{HPV})\end{array}$ & dysplasia & 3 & 20 & 4 & 5 & 0 & 2 & 3 & 41 & 78 \\
\hline $\begin{array}{l}\text { High grade SIL } \\
\text { CIN2-3 } \pm \text { HPV) }\end{array}$ & & 0 & 2 & 3 & 0 & 0 & 0 & 0 & 4 & 9 \\
\hline Atypia & & 2 & 8 & 0 & 5 & 0 & 2 & 0 & 67 & 84 \\
\hline Abnormal (ONL) & & 10 & 18 & 10 & 7 & 0 & 4 & 1 & 445 & 495 \\
\hline Total & & 30 & 101 & 32 & 34 & 1 & 15 & 8 & 1792 & 2013 \\
\hline
\end{tabular}

SIL = squamous intraepithelial lesion

Atypia = squamous or glandular cell changes of undetermined significance

ONL = outside normal limits (presence of infection or benign atypia)

$\dagger$ missing values not included in analysis. 
were controlled. However some trends were observed. Women with $\geqslant 10$ partners in life were 1.8 times more likely to have HPV than women with one lifetime sex partner and women aged between 15-19 yr who had had more than five sex partners in their lives were twice as likely to have an HPV infection than other age groups.

In common with our findings, a link between previous or current chlamydial infection and HPV infection was recently reported by Ley and coworkers. ${ }^{16} \mathrm{~A}$ history of chlamydial infection may act as a marker for subsequent predisposition to HPV infection and possible development of cervical neoplasia. ${ }^{28}$

The strongest association observed was between HPV infection and cervical dysplasia of any grade. Women with dysplasia or atypia were six times more likely to have HPV than other women; this is consistent with overseas studies, which have shown HPV infection to be a risk factor for dysplasia. ${ }^{241622-25}$

When we controlled for dysplasia in our analyses, the link with recent sexual activity disappeared for women with dysplasia, but women with normal cytology were at an even higher risk of HPV infection if they had more than five partners in the last year. In our study there were a number of women with normal cytology who were HPV positive. Most of these women were infected with HPV 16/18, types most frequently linked with development of dysplasia and cervical cancer. These women may have latent infections which are clinically and cytologically undetectable.

In the light of our findings, current cervical screening programmes with three yearly recall should perhaps be modified to annual recall for those women with a high number of recent sexual partners or a history of chlamydial infection.

The introduction of polymerase chain reaction (PCR) methodology has increased sensitivity levels for detection of HPV. ${ }^{11}$ Previous misclassification of HPV status ${ }^{16}$ may have obscured true HPV prevalence and association with cervical dysplasia in many studies. Current data from HPV-PCR studies indicate that there are shared risk factors for cervical cancer and HPV infection. ${ }^{16}$ The information gained from our study has presented opportunities for future investigations using sensitive PCR techniques. In view of the high incidence of cervical cancer in Maori women and the lack in our study of adequate access to this group, future work should perhaps be directed towards elucidating the possible role of HPV and other risk factors for cervical cancer in this population. The opportunity also presents itself to follow HPV-positive cytologically-normal women from our cohort in a longer term prospective study. The significance of latent HPV infections in a "normal" cervix is still undetermined.

This study was supported by a project grant from the Medical Research Council of New Zealand. We thank Ann Esler and Kay Lavill, Wellington Family Planning Clinic, for their work in patient contact, recruitment and administrative services, and Rowan Sweeney, NZCDC, for conducting virological analyses and data entry; we are very grateful to Paul Stehr-Green (NZCDC) for his assistance with statistical and epidemiological analysis. We also thank the staff of the Wellington and Porirua Family Planning Clinics for their support in recruiting participants even during busy and stressful clinic sessions. This paper is published with the permission of the Director-General of Health, New Zealand.

1 Department of Health. Area Health Board Service Planning Model for Sexually Transmitted Diseases. Appendix I. Model for Sexually Transmitted Diseases. Appendix

2 Reeves WC, Rawls WE, Brinton LA. Epidemiology of genital papillomaviruses and cervical cancer. Rev Infect Dis 1989;11:426-39.

3 Koutsky LA, Galloway DA, Holmes KK Epidemiology of genital papillomavirus infection. Epidemiol Rev 1988 10:122-63.

4 Reeves WC, Brinton LA, Garcia M, et al. Human papillomavirus infection and cervical cancer in Latin America. $N$ Engl f Med 1989;320:1437-41.

5 Kjaer SK, de Villiers E-M, Haugaard BJ, et al. Human papillomavirus, herpes simplex virus and cervical cancer incidence in Greenland and Denmark A populationbased cross-sectional study. Int $f$ Cancer 1988;41: 518-24.

6 National Health Statistics Centre. Cancer Data, new registrations and deaths 1987: New Zealand Department of Health, 1991.

7 Cox B, Skegg DCG. Trends in cervical cancer in New Zealand. NZ Med $\tilde{f}$ 1986;99:795-8.

8 Department of Statistics. Population. In: New Zealand Official 1990 Year Book. Wellington 1990:135-6,181

9 Pomare EW, de Boer GM. Hauhora: Maori Standards of Health (1970-84). MRC Special Report, Series 78. NZ Health Department 1988:124-37.

10 Kiviat NB, Koutsky LA, Paavonen JA, et al. Prevalence of genital papillomavirus infection among women attendin a college student health clinic or a sexually transmitted disease clinic. $\mathcal{F}$ Infect Dis 1989;159:293-302.

11 Bauer HM, Ting Y, Greer C, et al. Genital human papillomavirus infection in female university students as determined by a PCR-based method. $\mathscr{A} A M A$ 1991; 265:472-7

12 De Villiers E-M, Wagner D, Schneider A, et al. Human papillomavirus infections in women with and withou abnormal cytology. Lancet 1987;ii:703-6.

13 Kjaer SK, Engholm G, Teisen C, et al. Risk factors for cervical human papillomavirus and herpes simplex viru infections in Greenland and Denmark: a populationbased study. Am ₹ Epidemiol 1990;131:669-82.

14 Villa LL, Franco ELF. Epidemiologic correlates of cervical neoplasia and risk of human papillomavirus infection in asymptomatic women in Brazil. $f$ Natl Cancer Inst 1989;81:32-40.

15 NCI workshop. The 1988 Bethesda system for reporting cervical/vaginal cytology diagnoses. $f A M A 1989$; 262:931-4.

16 Ley C, Bauer HM, Reingold A, et al. Determinants of genital human papillomavirus infection in young women $\Im$ Natl Cancer Inst 1991;83:997-1003.

17 Brinton LA, Hammon RF, Huggins GR, et al. Sexual and reproductive risk factors for invasive squamous cell cervical cancer. $\mathcal{f}$ Natl Cancer Inst 1987;79:23-30.

18 Brinton LA, Reeves WC, Brenes MM, et al. Parity as a risk factor for cervical cancer. Am $\mathcal{f}$ Epidemiol 1989; 130:486-96.

19 Winkelstein W. Smoking and cervical cancer - current status: a review. Am $\mathcal{F}$ Epidemiol 1990;131:945-57.

20 Harris RWC, Brinton LA, Cowdell RH, et al. Characteristics of women with carcinoma in situ of the cervix uteri. Br $\mathcal{F}$ Cancer 1980;42:359-69.

21 Slattery ML, Overall JC, Abbott TM, et al. Sexual activity, contraception, genital infections and cervical cancer: support for a sexually transmitted disease hypothesis. $A m$ $\boldsymbol{f}$ Epidemiol 1989;130:248-58.

22 Meanwell CA, Cox MF, Blackledge G, Maitland NJ. HPV16 DNA in normal and malignant cervical epithelium 16 DNA in normal and malignant cervical epithelium: implications for the aetiology and

23 Kurman RJ, Schiffman MH, Lancaster WD, et al. Analysi of individual human papillomavirus types in cervical neoplasia: a possible role for type 18 in rapid progression. Am $\mathcal{F}$ Obstet Gynecol 1988;159:293-6.

24 Genital human papillomavirus infections and cancer: mem orandum from a WHO Meeting. WHO Bulletin 1987 65:817-27.

25 Pfister H. Human papillomaviruses and genital cancer. Adv Cancer Res 1987;48:113-47.

26 Hildesheim A, Reeves WC, Brinton LA, et al. Association of oral contraceptive use and human papillomaviruses in invasive cervical cancers. Int f Cancer 1990;45:860-4.

27 WHO Collaborative Study of Neoplasia and Steroid Con traceptives: invasive cervical cancer and combined oral contraceptives. BMf 1985;290:961-5.

28 Hare MJ, Thin RN. Chlamydial infection of the lowe genital tract of women. Br Med Bull 1983;39:138-44.$$
\text { genital tract of women. Br Med Bull 1983;39:138-44. }
$$

$$
\text { 㝘 }
$$

